\title{
Kontribusi Kebugaran Jasmani Terhadap Hasil Belajar Pendidikan Jasmani Olahraga Kesehatan (Penjasorkes) pada Pelajar SMP Pertiwi Siteba Padang
}

\author{
Berto Apriyano \\ bertoavano@gmail.com \\ Pendidikan Olahraga \\ Fakultas IImu Keolahragaan \\ Universitas Negeri Padang
}

\begin{abstract}
Abstrak : Berdasarkan pengamatan yang dilakukan pada pelajar SMP Pertiwi Siteba Padang menunjukkan bahwa hasil belajar yang dimiliki pelajar masih rendah khususnya mata pelajaran Penjasorkes. Hasil belajar Penjasorkes pada pelajar dipengaruhi oleh banyak faktor diantaranya diduga dipengaruhi oleh kebugaran jasmani. Penelitian ini bertujuan untuk menjelaskan hubungan dan kontribusi kebugaran jasmani terhadap hasil belajar Penjasorkes. Populasi penelitian ini adalah pelajar SMP Pertiwi Siteba Padang pada tahun ajaran 2014/2015 yang digunakan berjumlah 70 orang. Teknik pengambilan sampel dilakukan dengan cara proportionate stratified random sampling, dengan jumlah sampel yang digunakan sebanyak 58 orang dengan kesalahan 5\%. Data dikumpulkan dengan menggunakan instrumen tes kebugaran jasmani Indonesia (TKJI) untuk mengukur kebugaran jasmani dan untuk mengukur hasil belajar Penjasorkes menggunakan data sekunder nilai rapor semester 2 tahun ajaran 2014/2015 mata pelajaran Penjasorkes. Hasil penelitian adalah: (1) kebugaran jasmani memiliki hubungan signifikan dengan thitung $(2,167)>$ ttabel $(2,011)$ dan memberikan kontribusi sebesar $5,18 \%$ terhadap hasil belajar Penjasorkes.
\end{abstract}

Kata Kunci: Kebugaran Jasmani, Hasil Belajar Penjasorkes

\section{PENDAHULUAN}

Pendidikan dengan berbagai permasalahannya merupakan topik yang menantang untuk dibicarakan. Hal ini bukan hanya karena pendidikan sebagai kebutuhan manusia, tetapi pendidikan juga secara langsung menentukan kualitas pembangunan Sumber Daya Manusia (SDM) pada khususnya. Sementara itu dalam Undang-undang Sistem Pendidikan Nasional pada Bab II pasal 3 Undang-undang Republik Indonesia No. 20 Tahun 2003 yang berbunyi:

"Pendidikan nasional berfungsi mengembangankan kemampuan dan membentuk watak serta peradaban bangsa yang bermartabat dalam rangka 
Jurnal Menssana

Vol. 2, NO. 2, Mei 2017

ISSN : 2527-645X

mencerdasakan kehidupan bangsa, bertujuan untuk berkembanganya potensi pelajar agar menjadi manusia yang beriman dan bertakwa kepada Tuhan Yang 
Maha Esa, berakhlak mulia, sehat berilmu, cakap kreatif, mandiri dan menjadi warga negara yang demokratia serta bertanggung jawab."

Rendahnya kualitas Indonesia dipengaruhi oleh masih rendahnya mutu pendidikan mulai jenjang pendidikan dasar sampai perguruan tinggi. Untuk mencapai tujuan pendidikan nasional tersebut Sekolah Menengah Pertama sebagai bagian dari sistem pendidikan formal, melaksanakan kegiatan pembelajaran dalam seperangkat mata pelajaran wajib ataupun muatan lokal. Salah satu mata pelajaran di Sekolah Menengah Pertama adalah pendidikan jasmani olahraga kesehatan (Penjasorkes).

Berdasarkan fokus pembelajaran Pendidikan Jasmani Olahraga dan Kesehatan (Penjasorkes) di atas dapat dikatakan bahwa pengembangan aspek keterampilan gerak, pengetahuan gerak dan sikap merupakan tiga komponen utama dalam pelaksanaan pembelajaran. Sekolah berkewajiban atau mempunyai tanggung jawab membentuk pelajarnya yang sehat, baik secara jasmani maupun rohani. Untuk itu pendidikan jasmani disekolah perlu ditumbuh kembangkan, sehingga peserta tidak hanya sehat jasmani dan rohani, akan tetapi lebih dari itu pelajar dapat menyalurkan dan mengembangkan minat dan bakat setiap cabang olahraga yang ada pada dirinya. Akan tetapi dengan 2 (dua) jam per minggu yang di alokasikan dalam kurikulum pendidikan KTSP untuk mata pelajaran pendidikan jasmani olahraga kesehatan (Penjasorkes) dalam satu kali setiap minggu dirasakan belum maksimal.

Hasil belajar dipengaruhi oleh berbagai faktor, baik bersifat ekstern maupun bersifat intern. Menurut Slameto
(2010:54-72) faktor intern yang mempengaruhi belajar dan hasil belajar meliputi 1) Faktor Jasmaniah (Kebugaran Jasmani, Status Gizi, Cacat tubuh), 2) Faktor Psikologis (Inteligensi, Perhatian, Minat, Bakat, Motif, Kematangan, Kesiapan, Konsep Diri, Motivasi), 3) Faktor Kelelahan.

Sedangkan faktor ekstern yang mempengaruhi belajar dan hasil belajar meliputi 1) Faktor Keluarga (Cara orang tua mendidik, Relasi antar anggota keluarga, Suasana rumah, Keadaan ekonomi keluarga, Pengertian orang tua, Latar belakang kebudayaan), 2) Faktor Sekolah (Metode mengajar, Kurikulum, Relasi guru dengan siswa, Relasi siswa dengan siswa, Disiplin sekolah, Alat pelajaran, Waktu sekolah, Standar pelajaran di atas ukuran, Keadaan gedung, Metode belajar, Tugas rumah), 3) Faktor Masyarakat (Kegiatan siswa dalam masyarakat, Mass media, Teman bergaul, Bentuk kehidupan masyarakat).

Berdasarkan hasil observasi nyata yang ditemukan di SMP Pertiwi Siteba Padang. Bahwa pada semester 1 tahun ajaran 2014/2015 terdapat 40\% pelajar pada kelas VII, VIII dan IX yang mendapatkan nilai Penjasorkes di bawah Kriteria Ketuntasan Minimal (KKM) dengan Skor nilai : 80, sehingga mereka harus melakukan remedial hingga 3 kali baik melalui ujian praktek maupun ujian teori agar mereka bisa mendapatkan nilai KKM untuk di isikan kedalam raport akhir semester 1 tahun ajaran 2014/2015.

Menurut Hasan dan Asmawi dalam Abbas (2011:4) menyatakan bahwa suatu proses belajar mengajar dikatakan berhasil apabila $75 \%$ dari pelajar yang mengikuti pembelajaran tersebut mendapatkan nilai diatas KKM, dalam hal ini menggunakan KKM mata pelajaran penjasorkes. Dengan demikian 
dapat dinyatakan bahwa prestasi hasil belajar pelajar SMP Pertiwi Siteba Padang yang mengikuti mata pelajaran Penjasorkes ternyata belum pada tingkat yang diharapkan. Sedangkan Kriteria Ketuntasan Minimal (KKM) adalah skor batas ketuntasan penilaian yang diberikan guru kepada pelajar agar dapat meningkatkan kemampuan belajarnya sehingga dapat mencapai KKM yang telah ditentukan. KKM biasanya sudah ditetapkan oleh kebijakan Kementerian Pendidikan dan berlaku untuk seluruh Indonesia, akan tetapi dalam aplikasinya di sekolah guru diberikan kesempatan untuk menaikkan atau menurunkan skor nilai KKM, dengan beberapa faktor yang mendukung ataupun tidak mendukung ketercapaian KKM tersebut.

Kemudian peneliti juga masih menemui pelajar SMP Pertiwi Siteba Padang yang status gizinya rendah. Hal ini terlihat dari aktivitas pelajar dalam mengikuti pelajaran yang tampak loyo, lesu, kurang bersemangat, kurang serius dalam belajar bahkan tertidur dalam belajar, sehingga dalam pembelajaran Penjasorkes di sekolah tidak dapat terlaksana dengan baik sehingga hasil yang diharapkan tidak sesuai dengan tujuan yang diharapkan.

Oleh karena itu untuk mencapai kesehatan yang optimal perlu disusun angka kecukupan gizi sesuai dengan yang dianjurkan. Masih banyak ditemukan pelajar yang gizinya buruk, ini mungkin dikarenakan juga faktor ekonomi dan tingkat pendidikan dan pekerjaan orang tua. Padahal pendidikan dan kebutuhan gizi tersebut merupakan kritis dalam membentuk otak, watak, dan kepribadian. Setiap proses pendidikan dan kesehatan selalu diharapkan adanya keberhasilan dalam pembelajaran. Dalam upaya peningkatan belajar
Penjasorkes, peneliti memilih kebugaran jasmani.

Berdasarkan uraian di atas, peneliti tertarik untuk melihat lebih dalam hubungan dan mencari tahu bagaimana kontribusinya melalui sebuah penelitian antara lain, kebugaran jasmani terhadap hasil belajar Penjasorkes pada pelajar SMP Pertiwi Siteba Padang. Karena dengan adanya penelitian ini maka diharapkan dapat memberikan informasi bagi guru olahraga maupun guru bidang studi lainnya serta orang tua / wali murid murid dalam upaya membantu meningkatkan hasil belajar Penjasorkes melalui kebugaran jasmani pada pelajar SMP Pertiwi Siteba Padang.

\section{METODE PENELITIAN}

Penelitian ini menggunakan metode pendekatan kuantitatif dengan menggunakan Penelitian Korelasi (Correlational Research). Menurut Suharsimi Arikunto (2010:247) "Penelitian korelasi merupakan penelitian yang dilakukan untuk ada atau tidaknya, dan seberapa jauh ditemukan korelasi antara dua variabel atau lebih secara kuantitatif."

Pada metode penelitian ini berguna untuk mengungkapkan Hubungan serta Kontribusi Kebugaran Jasmani terhadap Hasil Belajar Penjasorkes maka jenis penelitian ini adalah korelasional dengan tujuan untuk mengungkapkan hubungan antara variabel bebas dengan variabel terikat berdasarkan besarnya korelasi. Selanjutnya, untuk menghitung besarnya Kontribusi digunakan Formula Indeks Determinasi, yaitu r2 x 100\%.

Populasi dalam penelitian ini adalah seluruh siswa/l SMP Pertiwi Steba Padang sebanyak 166 orang, sedangkan Teknik pengambilan sampel 
dalam penelitian ini adalah Proportionate Stratified Random Sampling, sebab itu peneliti menggunakan tingkat kepercayaan $95 \%$ dan tingkat kesalahan $5 \%$ terhadap populasi, maka jumlah sampel yang diambil adalah 58 orang.

Untuk mendapatkan data penelitian dilakukan pengukuran dengan cara sebagai berikut: Mengukur Kebugaran Jasmani dilakukan dengan Tes Kebugaran Jasmani Indonesia (TKJI) untuk siswa/l tingkat SMP, dan mengukur data Hasil Belajar Penjasorkes menggunakan data sekunder dari hasil nilai akhir raport sementara untuk semester 2 tahun ajaran 2014/2015.

\section{Variabel}

Tabel 1. Uji Normalitas Data Penelitian

\section{HASIL}

normalitas yang dilakukan terhadap data penelitian, Kebugaran Jasmani terhadap Hasil Belajar Penjasorkes ternyata hipotesis nol diterima, yaitu populasi berdistribusi normal. Dengan demikian, dapat disimpulkan bahwa data dari setiap variabel berdistribusi secara normal.

Data digunakan untuk menquii

hipotesis melalui bantuan KebugaranJasmani $58 \quad 0,1159 \quad 0,1163$ Normal Korelasi Product Moment dar yur.u. ( $\left.\mathbf{X}_{1}\right)$ Hipotesis 1 dan 2 diuji dengan Korelas Hasil Product Moment, sedangkan hipotests ke 4 diuji dengan korelasi ganda, kemudian dilanjutkan dengan analisis uji regresi pada taraf $0,05 \alpha$, dengan formula sebagai berikut:

$$
\mathrm{rxy}=\frac{n \cdot \sum x y-\left(\sum x\right)\left(\sum y\right)}{\sqrt{\left\{n \cdot \sum x^{2}-\left(\sum x\right)^{2}\right\}\left\{n \cdot \sum y^{2}-\left(\sum y\right)^{2}\right\}}}
$$

keterangan:

$r=$ Koefisien korelasi yang dicari

$\mathrm{X}=$ Variabel bebas

$y=$ Variabel terikat (Sugiyono, 2013:228)

Uji Korelasi Parsial untuk melihat hubungan secara murni :

1. Koefisien korelasi parsial antara $\mathrm{Y}$ dan $\mathrm{X}_{1}$, dimana $\mathrm{X}_{2}$ tetap.

Sumber: Hasil Pengolahan Data

Penelitian 2015

Dengan demikian, dari tabel $1 \mathrm{di}$ atas dapat disimpulkan bahwa data dari setiap variabel berdistribusi normal.

Sedangkan untuk melihat apakah masing-masing data variabel bebas (Kebugaran Jasmani) cendrung membentuk garis linear terhadap Hasil Belajar Penjasorkes. Data Kebugaran Jasmani memiliki kontribusi yang linear dengan Hasil Belajar Penjasorkes akan diuji dengan Ho. Kriteria pengujiannya yaitu apabila $F_{\text {hitung }}<F_{\text {tabel, }}$, untuk lebih jelas dapat dilihat di tabel 2 di bawah ini:

Tabel 2. Uji Linearitas $X_{123} Y$

$$
r_{y 1.2}^{2}=\frac{\left(1-r_{y 2}^{2}\right)-\left(1-r_{y 12}^{2}\right)}{1-r_{y 2}^{2}}
$$

\begin{tabular}{cccc}
\hline Variabel & $\mathbf{F}_{\text {hitung }}$ & $\begin{array}{c}\mathbf{F}_{\text {tabel }} \mathbf{\alpha} \\
\mathbf{0} \mathbf{0 5}\end{array}$ & Kesimpulan \\
\hline $\mathbf{X}_{\mathbf{1}}-\mathbf{Y}$ & 1,30 & 2,04 & Linear \\
\hline
\end{tabular}

Sumber: Hasil Pengolahan Data

2. Koefisien korelasi parsial antara $\mathrm{Y}$ dan $\mathrm{X}_{2}$, dimana $\mathrm{X}_{3}$ tetap

$$
r^{2}{ }_{y 2.3}=\frac{\left(1-r_{y 3}^{2}\right)-\left(1-r_{y 23}^{2}\right)}{1-r^{2}{ }_{y 3}}
$$

3. Koefisien korelasi parsial antara $\mathrm{Y}$ dan $\mathrm{X}_{3}$, dimana $\mathrm{X}_{1}$ tetap

$$
r^{2}{ }_{y 3.1}=\frac{\left(1-r_{y 1}^{2}\right)-\left(1-r^{2}{ }_{13}\right)}{1-r_{y 1}^{2}}
$$

Kesimpulan 
setiap variabel bebas terhadap variabel terikat memiliki kontribusi yang linear.

Setelah dilakukan Uji

Persyaratan Analisis dan hasil setiap variabel penelitian, di mana menunjukkan memenuhi persyaratan untuk dilakukan pengujian statistik, selanjutnya dilakukan pengujian hipotesis sebagai berikut:

Hipotesis 1 (satu): Kebugaran Jasmani memiliki hubungan yang signifikan terhadap Hasil Belajar Penjasorkes.

Hasil analisis Korelasi Product Moment menunjukkan $r_{\text {hitung }}(0.278)>$ $r_{\text {tabel }}(0.260)$, sedangkan hasil dari korelasi parsial didapat $t_{\text {hitung }}(1,733)>$ $t_{\text {tabel }}(1,675)$. Dengan demikian, dapat disimpulkan hipotesis kerja yang diajukan $\mathrm{H}_{\mathrm{o}}$ ditolak dan $\mathrm{H}_{\mathrm{a}}$ diterima, yang berarti Hipotesis 1 diterima, yaitu terdapat kontribusi yang signifikan Kebugaran Jasmani terhadap Hasil Belajar Penjasorkes.

Selanjutnya,

menghitung besarnya kontribusi melalui Indeks Determinasi $\left(r^{2}\right)$ sebesar $1,7332 \times 100 \%$ $=$, artinya Kebugaran Jasmani sebagai variabel independen berkontribusi sebesar 5,18\% terhadap Hasil Belajar Penjasorkes sebagai variabel dependen. Rangkuman analisis hasil uji keberartian untuk lebih lengkapnya dapat dilihat pada tabel 3 berikut:

Tabel3.Rangkuman Hasil Analisis Uji KeberartianKoefisienKorelasiKebugaranJ asmanidengan Hasil BelajarPenjasorkes
Pada uji hipotesis pertama yaitu kebugaran jasmani memiliki hubungan terhadap hasil belajar penjasorkes secara signifikan. Hal ini dibuktikan oleh penelitian relevan yang digunakan yaitu pada penelitian Harson(2002) kebugaran jasmani memberikan kontribusi terhadap hasil belajar penjasorkes sebesar 16,88\%. Kemudian pada penelitian Zuwirman(2010) kebugaran jasmani memberikan kontribusi terhadap hasil belajar penjasorkes sebesar $22,8 \%$. Kebugaran jasmani memberikan pengaruh terhadap hasil belajar penjasorkes karena kebugaran jasmani yang digunakan pada saat aktifitas proses belajar mengajar, baik saat pembelajaran praktek maupun teori.

Hasil penelitian yang peneliti temukan, untuk mengetahui kontribusi antar variabel dimana skor pada suatu variabel dapat digunakan untuk memprediksi skor pada variabel lainnya dilakukan analisis regresi linear sederhana. Dari hasil analisis diperoleh persamaan regresi $\hat{Y}=74,72+0,60 X$. Model persamaan regresi ini mengandung arti bahwa apabila kebugaran jasmani ditingkatkan pada satu skor, maka kecendrungan hasil belajar meningkat sebesar 0,60 pada konstanta 74,72.

Berdasarkan analisis data, telah terbukti bahwa kebugaran jasmani memiliki hubungan yang signifikan dan positif terhadap hasil belajar penjasorkes pada taraf signifikansi $\alpha=0,05$, terlihat pada analisis korelasi dan analisis korelasi parsial artinya kebugaran KoefisienKorelasi $\mathrm{rx}_{1} \mathrm{y}$ $t_{\text {hitung }}$ Kesimpialsmani memiliki hubungan positif yang 0.228 $1,733 \quad 1.675$ Signifikfermg berarti terhadap hasil belajar penjasorkes sebesar $5,18 \%$. Sehingga pada penelitian ini temuan kontribusinya 
Jurnal Menssana

Vol. 2, NO. 2, Mei 2017

lebih kecil dibandingkan dengan temuan kontribusi pada penelitian yang relevan.

\section{KESIMPULAN}

Sesuai dengan hasil kesimpulan dalam penelitian ini, maka dapat dikemukakan beberapa saran untuk perbaikan ke depannya, untuk. Dalam upaya peningkatan hasil belajar pada pelajar SMP Pertiwi Siteba Padang pada umumnya, dan peningkatan hasil belajar penjasorkes pada khususnya, diharapkan:

1. Bagi para guru pendidikan jasmani olahraga dan kesehatan, agar:

$>$ Menumbuhkan potensipotensi pelajar yang ada di sekolah, supaya pelajar berminat untuk berolahraga dan mendapatkan prestasi hasil belajar khususnya.

$>$ Membantu pelajarnya dalam mengembangkan potensi yang dimiliki atau sebagai pengontrol kegiatan pelajarnya di sekolah.

Menggunakan gaya mengajar yang menyenangkan, sehingga pelajar menyukai materi pendidikan jasmani olahraga dan kesehatan. Meningkatkan aspek psikologi bagi pelajar dengan mengarahkan dan membantu untuk menemukan konsep diri yang baik sehingga dapat meningkatkan hasil belajar penjasorkes khususnya.
ISSN : 2527-645X

Meningkatkan dan mengawasi aspek fisiologi pelajar dalam kebugaran jasmani dan status gizi dengan bekerja sama dengan pihak wali kelas dan wali murid.

2. Bagi sekolah, sebagai masukan dalam merencanakan, melaksanakan dan mengembangkan potensi pelajar di sekolahnya dan sebagai strategi untuk menunjang keberhasilan dalam hasil belajar pelajar.

3. Bagi siswa, supaya dapat meningkatkan potensi yang dimilikinya melalui aspek fisiologi (kebugaran jasmani dan status gizi) dan aspek psikologi sehingga diharapkan dapat memperoleh hasil belajar yang baik.

4. Peneliti berikutnya akan meneliti dengan variabel yang lebih banyak. Disebabkan penelitian yang dilakukan sangatlah terbatas dari segi variabel, jumlah sampel, tempat dan waktu penelitian. Maka diduga masih banyak variabel lain yang turut mendukung terhadap hasil belajar penjasorkes.

\section{DAFTAR PUSTAKA}

Abbas, Khairil. 2011. Kontribusi

Motivasi Belajar Penjasorkes dan

Kesegaran Jasmani terhadap Hasil Belajar Peserta Didik Kelas XI SMA N 4 Pekanbaru. Tesis. Padang Pascasarjana UNP.

Almatsier, Sunita. 2003. IImu Gizi SGO. Jakarta : Rineka Cipta. 
Almatsier, Sunita. 2002. Prinsip

Dasar Ilmu Gizi. Jakarta : Gramedia Pustaka Utama.

Adriana, Jumaini. 2008.

Pengaruh Konsep Diri dan Kemandirian terhadap Prestasi Belajar Histologi Mahasiswa Fakultas Kedokteran UKI Jakarta. Tesis. Surakarta : Universitas Sebelas Maret.

Arikunto, Suharsimi. 2007. Manajemen Penelitian. Jakarta : PT. Rineka Cipta.

Badan Standar Nasional Pendidikan. 2007. Kurikulum Tingkat Satuan Pendidikan, Jilid 1. Jakarta : Bimatama Raya.

Bawardin. 2010. Kontribusi Status Gizi dan Persepsi Siswa Tentang Gerak Terhadap Kemampuan Motorik Siswa Sekolah Dasar Kecamatan Argamakmur. Tesis. Padang : PPS UNP.

Depdiknas.(2006). Panduan

Pengembangan Silabus Pembelajaran Mata Pelajaran Penjasorkes (KTSP). Jakarta.

Fardi, Adnan, dkk. 2012. Silabus dan Hand-Out Mata Kuliah Statistik. Padang: UNP.

Harson, Denis. 2003. Hubungan Antara Satatus Gizi dan Keegaran jasmani Terhadap Hasil Belajar Siswa di SMU Cendana Pekanbaru. Tesis. Padang : Universitas Negeri Padang.

Harsuki. 2003. Perkembangan Olahraga Terkini. Jakarta : Raja Gravindo.

Irianto, Agus. 2004. Statistik Konsep Dasar \& Aplikasinya. Jakarta : Kencana Prenada Media.

Irianto, Joko. P. 2007. Panduan Gizi Lengkap Keluarga dan Olahragawan. Yogyakarta.

Ismaryati. 2008. Tes dan Pengukuran Olahraga, Surakarta: Lembaga Pengembangan Pendidikan
(LPP) dan UPT Penerbit dan Percetakan UNS (UNS Press) Universitas Sebelas Maret.

$$
\text { Jalaluddin Rakhmat, 1974, }
$$
Psikologi Komunikasi, Bandung : Remaja Rosdakarya.

Kemenkes RI. 2011. Keputusan Menteri Kesehatan Republik Indonesia N0.1995/Menkes/SK/XII/2010 tentang Standar Antropometri Penilaian Status Gizi Anak.

Kemendiknas RI. 2010.

Pedoman Teknis Pemetaan Kebugaran Jasmani Pelajar (Tes Kesegaran Jasmani Indonesia) Tahun 2010.

Komaini, Anton. 2010. Kontribusi

Aktivitas Bermain dan Status Gizi terhadap Keterampilan Motorik Kasar Murid Taman Kanak-Kanak Kecamatan Padang Utara. Tesis : UNP.

Lutan, Rusli. (2000). Pengukuran dan Evaluasi Penjaskes. Jakarta: Departemen Pendidikan Nasional.

Muhammad Ali. (2011). Kontribusi Status Gizi dan Motivasi Belajar Terhadap Kesegaran Jasmani. Volume 1 Edisi 2, Desember 2011 ISSN: 2088-6802. Diunduh tanggal 7 Mei 2015 dari http://www.journal.unnes.ac.id.

Nurhasan. 2001. Buku materi pokok tes dan Pengukuran. Departemen Pendidikan dan Kebudayaan. Jakarta : Rineka Cipta .

Purwanto, Ngalim. 2007. Psikologi Pendidikan, Jakarta: Remaja Rosdakarya.

Riduwan. 2012. Pengantar Statistika Sosial. Bandung : Alfabeta.

Rosita, H.S., Rahmatina, B.H., \& Susila, S. (2014). Hubungan Status Gizi dengan Prestasi Belajar Siswa Sekolah Dasar Negeri 01 Guguk Malintang Kota Padang. Diunduh tanggal 14 April 2015 dari http.//www.jurnal.fk.unand.ac.id. 
Vol. 2, NO. 2, Mei 2017

R.B.Burn. 1993 Konsep Diri.

Jakarta : Arcan.

Sardi, Beni. 2013. Pengaruh

Senam Kesegaran Jasmani 2008,

Senam Ayo Bersatu dan Status Gizi terhadap Kesegaran Jasmani. Tesis. Padang : Pascasarjana UNP.

Slameto. 2010. Belajar dan Faktor-Faktor yang Mempengaruhinya . Jakarta : Rineka Cipta.

Sudijono, Anas. 2011. Pengantar

Evaluasi Pendidikan. Jakarta : PT Raja Grafindo Persada.

Sudjana. 1992. Metode

Statistika. Bandung: Tarsito.

Sugiyono. 2011. Metode

Penelitian Kuantitatif, Kualitatif dan R\&D, Bandung: Alfabeta.

Suprijono, Agus. 2014.

Cooperative Learning (Teori \& Aplikasi Pakem). Yogyakarta. Pustaka Pelajar.

Syafruddin. 2011. IImu

Kepelatihan Olahraga. Padang : UNP PRESS.

Syahara, Sayuti. 2010. Pertumbuhan dan Perkembangan Fisik Motorik. Padang : FIK UNP.

Widiastuti. 2011. Tes dan

Pengukuran Olahraga. Jakarta : PT. Bumi Timur Jaya. 